\title{
A PERCEPÇÃO DE DOCENTES DO CURSO DE GRADUAÇÃO EM ENFERMAGEM E OBSTETRÍCIA DE UMA UNIVERSIDADE PÚBLICA FEDERAL SOBRE A INTEGRAÇÃO DOCENTE ASSISTENCIAL*
}

SHIMIZU, H.E. A percepção de docentes do curso de graduação em enfermagem e obstetrícia de uma universidade pública federal sobre a integração docente assistencial. Rev.latino-am.enfermagem, Ribeirão Preto, v. 7, n. 5, p. 51-57, dezembro 1999.

Este estudo tem por objetivo explicitar a percepção de docentes do curso de graduação em Enfermagem de uma Universidade pública do Distrito Federal sobre a Integração Docente Assistencial (IDA). Para compreender a vivência das enfermeiras docentes, optou-se pela vertente metodológica da fenomenologia, segundo a modalidade da estrutura do fenômeno situado. Desvelou-se que: a IDA é um desafio a ser superado pelos enfermeiros docentes e assistenciais; a infra - estrutura adequada é imprescindivel para a efetiva integração entre o ensino e a assistência e, finalmente que a IDA beneficiará ambas as instituições: ensino e assistência.

UNITERMOS: integração, ensino, assistência, enfermagem

\section{INTRODUÇÃO}

A minha vivência, durante onze anos, em um hospital público e de ensino que tem implantado a Integração Docente Assistencial (IDA) desde a sua fundação, e posteriormente o meu ingresso no curso de pós-graduação, motivaram-me a aprofundar estudos sobre esta questão.

No curso de Mestrado, quando realizei a disciplina Administração em Serviços de Enfermagem, estudei essa temática considerando a percepção das enfermeiras assistenciais que vivenciavam a IDA com a disciplina de Administração aplicada à Enfermagem do curso de graduação em Enfermagem da EEUSP.

Atualmente, no curso de Doutorado, e tendo oportunidade para refletir e discutir sobre questões relativas à formação do enfermeiro na disciplina Problemática de Enfermagem, percebo que para melhorar a qualidade do ensino de Enfermagem temos que resgatar, rever e valorizar a IDA.

Acredito que a IDA possa contribuir para que os docente superem a dicotomia entre a teoria e a prática, devido a sua maior aproximação com campo prático. Como conseqüência, possivelmente terão ainda melhores preparo técnico e conhecimento da realidade.

Além disso, percebo na IDA um caminho para melhor articulação entre os enfermeiros assistenciais e de ensino e, em conseqüência, oportunidades para refletirem sobre a qualidade de assistência prestada aos pacientes. Acredito ainda, que os resultados de sua aplicação poderão tornar os campos de estágio mais adequados para o desenvolvimento do ensino de Enfermagem, onde os alunos terão maiores oportunidades para aplicar a teoria estudada em um campo prático.

A IDA tem sido objeto de preocupação dos enfermeiros assistenciais e enfermeiros docentes há longa data, exigindo esforços desses profissionais para atingir os moldes desejáveis de aplicação.

No Brasil, a partir da reforma universitária de 1968, intensificaram-se os estudos sobre a IDA, quando ela foi considerada elemento importante para a qualificação do profissional a ser formado e também para a melhoria da qualidade de assistência a ser prestada.

Todavia, apesar dos aspectos positivos, são várias as dificuldades enfrentadas pelas instituições de ensino e serviços de saúde para a implantação da IDA.

Uma das dificuldades, segundo DUARTE (1990), advém da abrangência do assunto, demonstrada em sua

\footnotetext{
* Trabalho apresentado à disciplina problemática de Enfermagem do curso de Doutorado Interunidades da Escola de Enfermagem/ Escola de Enfermagem de Ribeirão Preto da Universidade de São Paulo, coordenado pelas Professoras Doutoras: Victória Secaf e Raquel Rapone Gaidzinsk

** Doutoranda do Programa Interunidades da Escola de Enfermagem/Escola de Enfermagem de Ribeirão Preto da Universidade de São Paulo. Bolsista pesquisador do CNPq
} 
própria conceituação: "União de esforços em um processo crescente de articulação entre instituição de educação e de serviços de saúde, adequados às necessidades reais da população, à produção de conhecimentos e a formação de recursos humanos necessários em um determinado contexto da prática de serviços de saúde e de ensino" (BRASIL. MEC/SESU, 1981).

Para LAGANÁ (1986) um dos entraves para a IDA é a metodologia baseada na transmissão de conhecimentos, com maior ênfase ao ensino do que na aprendizagem, ou seja, reforçando a idéia de que a universidade não tem outro papel e/ou compromisso com a sociedade a não ser o de criar, preservar ou transmitir o saber, deixando de lado a missão fundamental de prestar serviços.

KURCGANT \& CIAMPONE (1987); OLSCHOWSKY (1995) percebem que as políticas e estruturas dos serviços de saúde e de ensino muitas vezes impossibilitam a participação mais efetiva, tanto dos enfermeiros assistenciais como dos enfermeiros docentes na IDA.

Outra dificuldade apontada por PADILHA (1991) refere-se ao fato dos docentes estarem mais envolvidos com as atividades de pesquisa do que com a de ensino, com o agravante de colocarem em segundo plano a prática assistencial. Essa dificuldade leva os docentes a distanciarem-se das situações práticas do cotidiano da Enfermagem, tornando-se teóricos ineficientes na rotina das instituições de saúde. Em contrapartida, os enfermeiros assistenciais se envolvem de forma tão profunda com as atividades rotineiras do cotidiano de trabalho que deixam de lado a educação continuada, como conseqüência tornam-se enfermeiros pouco atualizados.

Dessa forma, para evitar que se instale a dicotomia absoluta entre o ensino e a assistência, deve se destacar em plano prioritário o compromisso das instituições de ensino e de saúde para com a IDA.

Para TORRES et al. (1984); PIRES et al. (1982) o sucesso efetivo da IDA depende da clara definição dos objetivos educacionais e assistenciais; do estabelecimento de responsabilidades, tanto para o ensino como para o serviço; da reforma dos dois sistemas e dos critérios de avaliação capazes de mensurar resultados obtidos.

Segundo PADILHA (1991); EGRY et al.(1991); REZENDE (1989) a implantação da IDA exige modificações conceituais, estruturais, estratégicas e operacionais profundas, das instituições de saúde e de ensino. Além disso, exige que os docentes que atuam nas universidades atualizem a teoria e a prática, partindo da realidade, interpretando, intervindo e reinterpretando essa realidade, reconhecendo nela a vinculação do processo saúde-doença aos determinantes sociais a que estão expostos os grupos populacionais.

Neste sentido, verifica-se que a IDA vem sofrendo transformações, e que estas têm ocorrido de forma oscilante, algumas vezes avançando e outras retrocedendo, gerando expectativas e insatisfações para enfermeiros de campo, docentes e alunos.

Cabe ressaltar que, atualmente, existe vasto material bibliográfico sobre o assunto. Além disso, verifica-se que já se tornou habitual sua utilização, não apenas nos hospitais universitários, mas pelas instituições de saúde, como exercício para exercer funções educativas, assistenciais e de ensino.

Para o ensino de Enfermagem, percebe-se que na IDA estão embutidas as bases prospectivas para a concretização de uma das estratégias educativas que efetivamente promovam, recuperem e reabilitem a saúde de uma comunidade.

Assim, este estudo tem como objetivo: Desvelar como os docentes do curso de graduação em Enfermagem e Obstetrícia de uma universidade pública federal de Brasília percebem a IDA.

\section{A TRAJETÓRIA METODOLÓGICA}

O fenômeno, objeto desta pesquisa, está inserido no contexto das vivências individuais das enfermeiras docentes com o ensino teórico e de campo no curso de graduação em Enfermagem.

Desse modo, considerei adequado encaminhar este estudo dentro das perspectivas da pesquisa qualitativa, adotando a modalidade da estrutura do fenômeno situado ou análise fenomenológica, segundo o referencial de MARTINS \& BICUDO (1989).

Nesta modalidade de pesquisa, segundo MARTINS \& BICUDO (1989), procura-se abordar o fenômeno como aquilo que se manifesta por si mesmo, de modo que não o parcializa ou o explica a partir de conceitos prévios, de crenças ou de afirmações sobre o mesmo.

Estes autores esclarecem, também, que busca-se refletir sobre a natureza do fenômeno na sua totalidade e essência. Assim sendo, parte-se do suposto que os fenômenos, bem como sua própria essência, são percebidos pelos sujeitos, pelo sentido e intuição. A intuição da essência vai além da percepção do fenômeno, estando relacionada ao sentido do vivencial. Neste sentido, valoriza-se também a consciência, como sendo consciência de alguma coisa, e que está sempre voltada para o mundo exterior, para os homens, para suas ações, seu ego, seus sentimentos e sua imaginação, ou seja, a realidade, a exterioridade, a existência do objeto percebido e o seu próprio caráter dependem das estruturas da consciência intencional (MARTINS \& BICUDO, 1989). 
Nesta perspectiva, valoriza-se o mundo vida, isto é, aquilo que o homem percebe a partir da sua experiência de vida. E isto, na realidade, representa a sua concepção de homem, mundo e universo.

Dessa forma, o rigor da pesquisa fenomenológica não está em uma teoria, no aceitá-la ou rejeitá-la segundo leis da probabilidade, mas sim em chegar a um pensar. $\mathrm{O}$ rigor que se busca é o rigor epistemológico. Este rigor se dá ao se poder penetrar no discurso dos sujeitos de maneira que este se torne esclarecedor.

Neste sentido, a fenomenologia pode ser compreendida como o estudo das essências e dos significados articulados no discurso, através dos quais vai se mostrar chegando à coisa mesma, que se constitui na tentativa de reencontrar a verdade nos dados originários da experiência.

Entretanto, é preciso ainda considerar que, para que o fenômeno se mostre, não basta vivê-lo, pois na imersão, a amplitude de visão se restringe. A compreensão exige, pois, transcender esta perspectiva e espreitar as diferentes possibilidades, através do ver e do sentir do outro. (MACHADO, 1989; GAIDZNSKI, 1994; KREUTZ, 1993).

Portanto, o mundo fenomenológico é não o do ser puro, mas o sentido que aparece na interseção das experiências passadas e presentes de cada um, e na interseção delas com as dos outros, contemplando a subjetividade e intersubjetividade envolvidas nessas relações.

Para conduzir uma pesquisa nesta modalidade é necessário situar o fenômeno em uma região de inquérito onde o sujeito está vivenciando esse fenômeno. Assim, a região ontológica onde o fenômeno foi inquirido diretamente constituiu-se do contexto do Departamento de Enfermagem da Faculdade de Ciências da Saúde de uma universidade pública do Distrito Federal. As enfermeiras docentes desta Universidade vivenciam a situação de ensino teórico e prático do curso de graduação em Enfermagem e Obstetrícia. O ensino prático é realizado em vários hospitais da região, porém a maioria dos docentes utiliza-se do Hospital Universitário.

Cabe ressaltar que os docentes desta universidade têm tentado implantar Integração Docente Assistencial em algumas Instituições de saúde da região, inclusive no Hospital Universitário. No entanto, essas experiências têm ocorrido de forma isolada e assistemática, isto é, em algumas Unidades e por algum tempo.

Seguindo-se a metodologia adotada, o número de enfermeiras docentes não foi definido a priori. Assim, $a$ análise das descrições foi sendo processada até que ocorresse a invariância do fenômeno estudado. Foram realizadas duas entrevistas.

Inicialmente, foi explicado às enfermeiras sujeitos do estudo a finalidade da pesquisa e garantia do anonimato da sua participação. As entrevistas foram realizadas pela pesquisadora com o auxílio de um gravador e, posteriormente, transcritas integralmente.

Segundo MARTINS \& BICUDO (1989) a entrevista é uma técnica bastante adequada para se obter dados relevantes sobre o mundo-vida do sujeito.

Assim, ao entrevistar cada enfermeira, objetivouse conseguir descrições detalhadas das suas vivências, sem contudo produzir estímulos pré-categorizados para respostas desejadas. A pergunta orientadora foi: "O que é Integração Docente Assistencial para você?"

Procurou-se desenvolver um questionamento não preconceituoso, livre de juízo de valor, apresentando tópicos relevantes e significativos à captação do fenômeno IDA, de forma não restritiva, deixando-as falar livremente e não sendo estabelecido tempo de duração. Assim, a pergunta serviu de base para orientar o pensamento. As descrições espontâneas das enfermeiras foram de importância fundamental para a compreensão de seus mundos-vidas.

\section{RESULTADOS}

Para análise do conteúdo das entrevistas seguiram-se os momentos metodológicos definidos por MARTINS \& BICUDO (1989): descrição, redução e compreensão.

A análise das descrições foi iniciada após a realização da segunda entrevista, quando também verificou-se que os conteúdos se repetiam nos discursos. Inicialmente os discursos foram enumerados e lidos por inteiro, atenta e criteriosamente, com a finalidade de apreender-se o sentido global, mas ainda sem interpretar ou identificar os atributos neles contidos.

A seguir, buscou-se, nas descrições de cada discurso, a presença evidente da essencialidade do fenômeno IDA. Assim, as unidades de significado foram identificadas, postas em destaque em negrito e, uma a uma, numeradas entre colchetes.

Após a obtenção das unidades de significado, procedeu-se à redução fenomenológica, através da análise ideográfica, onde as descrições espontâneas do sujeito foram reescritas na linguagem da pesquisadora, que procurou dar maior clareza ao discurso. Posteriormente, buscou-se identificar e agrupar as unidades de significado interpretadas de cada discurso que apresentavam um tema comum. Desse agrupamento, evidenciaram-se os seguintes temas:

- os objetivos da IDA;

- as dificuldades para a implantação da IDA;

- a infra-estrutura necessária para implantar a IDA;

- uma alternativa para implantar a IDA;

- os benefícios da IDA. 
Foi realizada também a análise ideográfica dos dois discursos, que representa a estrutura individual do fenômeno IDA, desvelada a partir da análise do discurso de cada sujeito, o que será apresentado a seguir:

\section{Análise ideográfica do discurso 1}

Para este sujeito, a IDA deve ter como objetivos: a preocupação com a melhoria da qualidade de assistência prestada e com as condições necessárias para desenvolver o ensino do curso de graduação em Enfermagem com qualidade.

Contudo, percebe que o hospital tem mostrado interesse na IDA apenas para suprir a deficiência de pessoal da instituição. Neste sentido, este docente percebe que, atualmente, os professores têm sido coerentes, por não concordarem em assumir o hospital apenas como mão de obra. Entretanto, acredita que o modelo de IDA em que o docente assume cargos possa ser viável, caso haja compromisso dos mesmos com a melhoria da qualidade de assistência prestada e com as condições necessárias e adequadas para desenvolver o ensino de graduação em Enfermagem.

Aponta também outras dificuldades para a implementação da IDA, como a falta de envolvimento das instituições de ensino e assistência para com a IDA, ausência de estímulos aos profissionais e falta de profissionais capacitados para assumi-la.

Além disso, revela que não há infra-estrutura adequada para sua implantação, pois os docentes já convivem com sobrecarga de trabalho, devido ao déficit de professores, a necessidade de realizarem pesquisas e atividades de extensão e ao fato dos enfermeiros assistenciais terem inúmeras atividades para serem realizadas no cotidiano de trabalho.

Salienta também que a ausência de contrato entre as instituições formalizando a IDA dificulta sua operacionalização. Por fim, ressalta a necessidade de criar uma proposta de integração adequada e viável para esta realidade.

Este sujeito afirma que, antes de implantar-se a IDA, há necessidade dos enfermeiros docentes e assistenciais discutirem alguns aspectos, como por exemplo: as suas expectativas e desejos com relação a IDA, a necessidade de redimensionar o quantitativo de profissionais, bem como as atividades a serem desenvolvidas pelos mesmos e, por fim, as estratégias para formalizar a proposta de IDA entre as instituições de ensino e assistência.

$\mathrm{Na}$ sua percepção, uma das estratégias para implementar a integração, seria a maior participação dos docentes no cotidiano das unidades utilizadas como campos de estágio pelos seus alunos.

Apesar das inúmeras dificuldades para a sua implantação, acredita que a integração entre ensino e assistência poderá trazer benefícios para ambas instituições, além de permitir ao professor participar no processo de sua construção e, neste contexto, os docentes teriam ainda a possibilidade de manter atualizadas as suas habilidades e conhecimentos.

\section{Análise ideográfica do discurso 2}

Para este sujeito, a finalidade da IDA é integrar a Universidade com a assistência, isto é, com os hospitais e os serviços da rede básica.

No entanto, percebe várias dificuldades para a implementação da IDA, como a falta de vínculo sistemático dos docentes com o campo, a sobrecarga de trabalho dos docentes e a resistência da equipe de Enfermagem das instituições de saúde em aceitar a participação do docente no cotidiano de trabalho, sobretudo no modelo em que o docente assume os cargos de chefia do hospital. Além dessas dificuldades, revela que a equipe médica também não se dispõe a discutir as propostas de IDA apresentados pelos enfermeiros docentes.

Assim, na percepção deste sujeito, um dos entraves para implantar a IDA reside no medo dos profissionais, tanto da equipe de Enfermagem como da equipe médica, de perderem para os enfermeiros docentes as posições de poder ocupadas nas instituições de saúde. Neste sentido, este sujeito revela que na IDA estão embutidas disputas pelo poder conferidos pelos cargos existentes nas instituições de saúde.

Este sujeito aponta também que há falta de infraestrutura para se implantar a IDA, principalmente da universidade, por não terem um quadro de pessoal adequado, que permita deslocar alguns professores para se dedicarem às atividades desenvolvidas no hospital. Revela também que as exigências feita pela universidade aos professores (o ensino, a pesquisa e a extensão) impedem seu envolvimento com a IDA. Nesse sentido, acredita que a universidade precisaria flexibilizar as cobranças feitas aos mesmos, no que se refere a quantidade de atividades, para que possam se dedicar também a IDA.

Apesar de várias dificuldades, para este sujeito é importante que a IDA seja consolidada para tentar garantir uma melhor articulação entre ensino e assistência e, conseqüentemente, para melhorar a qualidade do ensino de Enfermagem. Dessa forma, tem feito várias tentativas para implantar a IDA, tanto nas instituições de saúde que tem utilizado como campo de estágio, como em outras que ainda não recebem alunos da Enfermagem.

Seguindo-se a trajetória fenomenológica, as unidades de significado interpretadas foram submetidas à análise nomotética. Preliminarmente foi feito um 
agrupamento de todas unidades de significado interpretadas dos dois discursos, dentro de suas respectivas categorias e organizados em um quadro nomotético, que não será aqui apresentado.

\section{SÍNTESE}

O último passo constituiu-se em uma síntese que integrou as idéias gerais desveladas através de uma descrição consistente da estrutura situada do fenômeno.

Assim, foi possível obter algumas generalidades, representando os níveis de compreensão do fenômeno que necessariamente resultam da intersubjetividade do pesquisador/sujeito.

Os docentes explicitaram que a IDA deve ter como objetivo a integração entre a Universidade e os Serviços de Saúde (hospitais e a rede básica: Postos de Saúde, Unidade Mista e outros serviços), e deve ter como prioridade a preocupação com a melhoria da qualidade de assistência prestada, bem como com as condições necessárias para o desenvolvimento do ensino de Enfermagem com qualidade.

Nessa perspectiva, para os docentes a IDA é um desafio a ser vivenciado. Contudo, nas várias tentativas de implantação dessa proposta, deparam-se com inúmeras dificuldades.

Segundo a percepção dos docentes, os dirigentes dos hospitais tem visualizado a IDA apenas como uma possibilidade para resolver o problema da deficiência de pessoal e, nesse contexto, comumente correm o risco de assumirem as atividades no hospital apenas como mão de obra. Desse modo, ressaltaram a necessidade de se resgatar junto a essas instituições a valorização da IDA, onde se tenha como compromisso principal, a real integração entre a universidade e o serviço.

Atualmente, os docentes percebem que uma das possibilidades para a implementação da IDA seria por meio de campos de estágio, que os professores utilizam com maior freqüência. Acreditam que esta forma de integração possibilitaria uma maior união entre enfermeiros docentes e assistenciais. No entanto, revelaram que, neste modelo, a integração não é sistemática, pois o contato dos docentes com o hospital ocorre apenas nos períodos de estágio dos alunos. Quando o docente está envolvido com as atividades teóricas, as atividades assistenciais são assumidas apenas pelas enfermeiras do hospital. Desvela-se, portanto que esta condição descaracteriza a IDA.

Evidenciou-se, também, que a estrutura atual (ensino e serviço) impede maior envolvimento dos profissionais com a IDA. Os docentes do Departamento de Enfermagem, devido ao quadro reduzido, já possuem sobrecarga de trabalho com as atividades acadêmicas, além de assumirem atividades de pesquisa e extensão. Os enfermeiros assistenciais, por sua vez, são muito absorvidos pelas atividades do cotidiano de trabalho. Assim sendo, enfatizaram a necessidade de se rediscutir a infra-estrutura necessária para a implantação da IDA.

Neste sentido, percebem que há necessidade de reivindicar maior número de profissionais para as instituições de ensino e de saúde e de redimensionamento das atividades dos enfermeiros docentes e assistenciais, de forma a possibilitar a participação mais efetiva dos mesmos na IDA.

Seguindo essa linha de raciocínio, ressaltaram também a necessidade de discussão sobre as expectativas e desejos dos enfermeiros docentes e assistenciais em relação à IDA. Explicitaram também que, posteriormente, estes profissionais precisam tentar estruturar uma proposta de IDA adequada para cada realidade específica.

Acreditam que a oportunidade de discussão entre os profissionais (enfermeiros assistenciais e enfermeiros docentes) acerca das expectativas, formulação de objetivos e formas de operacionalização, ajuda também a diminuir a idealização destes profissionais sobre a IDA. Como conseqüência, a proposta poderá ter uma maior aproximação das necessidades desta realidade.

Além disso, a implementação dessas etapas ajuda a minimizar as resistências e conflitos, minimizando, conseqüentemente, os preconceitos dos profissionais das instituições (ensino e assistência) quanto à IDA.

Desta forma, evidenciou-se neste estudo que estas fases são fundamentais, e constituem o esqueleto principal da IDA. Assim, fica evidente que a desconsideração de qualquer uma destas etapas dificultará a viabilização da proposta, além de a descaracterizar.

Além das necessidades aqui evidenciadas, a meu ver, outro aspecto importante para facilitar a implantação da integração é a participação de representantes dos órgãos deliberativos das instituições de ensino e de saúde na construção da proposta, o que conseqüentemente facilitará a formalização do contrato entre as instituições de ensino e de assistência.

Em suma, apesar da inúmeras dificuldades para a implantação da IDA, desvela-se que os docentes acreditam que ela pode trazer grandes benefícios para as instituições de ensino e assistência, bem como para os docentes. Além disso, apontam a sua construção como uma oportunidade para atualização dos docentes que, conseqüentemente, trará melhorias na qualidade do ensino.

Os resultados deste estudo ajudaram compreender que a IDA é um desafio a ser superado tanto pelos enfermeiros docentes como assistenciais. A meu ver, a ausência de discussões entre os enfermeiros docentes e assistenciais tem sido um grande fator 
dificultador para a sua implantação. Assim sendo, percebo que essas discussões são fundamentais e, deveriam enfocar as expectativas e os desejos desses profissionais com relação a IDA, a formulação de seus objetivos, as formas de operacionalização. Acredito ainda, que deve ser elaborada uma proposta de integração para cada realidade específica.

Em suma, percebo que este estudo levanta algumas questões importantes sobre a IDA, que me despertam e me impulsionam a continuar refletindo sobre muitos pontos significativos que surgiram nesta caminhada. Contudo, acredito que seria necessário e importante a realização de outras pesquisas sobre este assunto, envolvendo as opiniões de alunos, enfermeiros assistenciais e usuários, não como a soma das partes mas, como uma unidade própria.

Finalmente, proponho que repensemos a nossa prática, quer seja na assistência ou no ensino, tanto sobre as questões aqui levantadas, bem como sobre outros possíveis caminhos para consolidação da IDA, e que sejam importantes para os pacientes, alunos, enfermeiros docentes e assistenciais.

\section{THE PERCEPTION OF FACULTY MEMBERS FROM THE NURSING UNDERGRADUATE PROGRAM OF A PUBLIC FEDERAL UNIVERSITY ON THE CLINICAL - FACULTY NURSES INTEGRATION MODEL}

The purpose of this study is to identify and analyse the perception of the faculty members from the nursing undergraduate program of a public federal university on the clinical - faculty nurses integration model. In order to understand the faculty's experiences, a phenomenological approach was used, according to the structural component of the chosen phenomenon. The results showed that this faculty - clinical nurses integration model is seen an a challenge to both faculty and nurse professionals; that adequate resources are crucial for an effective integration between health care practice and education; and finally, that the integration model can bring benefits to both institutions.

\section{LA PERCEPCIÓN DE LOS DOCENTES DEL CURSO DE PRE-GRADO EN ENFERMERÍA Y OBSTETRICIA DE UNA UNIVERSIDAD PÚBLICA DEL DISTRITO FEDERAL SOBRE LA INTEGRACIÓN DOCENTE ASISTENCIAL}

El presente estudio tiene por objetivo, explicar la percepción de los docentes del curso de graduación en enfermería y obstetricia de una universidad pública del Distrito Federal sobre la Integración Docente Asistencial (IDA). Para comprender la vivencia de los docentes, se optó por la vertiente metodológica de la fenomenología, según la modalidad de la estructura del fenómeno situado. Se desveló que: la IDA es un desafio a ser vivido por los enfermeros docentes y asistenciales; la infraestructura adecuada es imprescindible para la efectiva integración entre la docencia y la asistencia; la IDA beneficiará a las instituciones de docencia y asistencia.

TÉRMINOS CLAVES: enfermería, integración, docencia y asistencia

\section{REFERÊNCIAS BIBLIOGRÁFICAS}

01. BRASIL. Ministério da Educação e Cultura. Secretaria do ensino superior. Programa de integração docente - assistencial - IDA. Brasília: MEC-SESU-CCS, 1981.32p. (Caderno da ciências da saúde, n.3).

02. DUARTE, N.M.N. Integração docente assistencial entre uma instituição de ensino e um hospital de ensino de Porto Alegre: experiência de um grupo de trabalho. Rev.Gaúch.Enfermagem, v. 11, p. 52-58, 1990.

03. EGRY, E.Y. et. al. Integração docente assistencial: A transformação da qualidade do ensino e da assistência em saúde coletiva através da condução praxiológica. Rev.Esc.Enfermagem USP, v. 25, n. 2, p. 169-176, 1991.
04. GAIDZINSK, R. R. O dimensionamento de pessoal de enfermagem segundo a percepção de enfermeiras que vivenciam essa prática. São Paulo, 1994. 253p. Tese (Doutorado) - Escola de Enfermagem, Universidade de São Paulo.

05. KREUTZ, I. O trabalho em equipe na enfermagem. São Paulo, 1993. 93p. Dissertação (Mestrado) Escola de Enfermagem, Universidade de São Paulo.

06. KURCGANT, P.; CIAMPONE, M. T. Um ponto de reflexão sobre a integração docente assistencial. Enfoque, v. 15, n. 3, p. 62-63, 1987.

07. LAGANÁ, M. T. C. Integração docente assistencial. Enfoque, v. 14, n. 1, p. 12-15, 1986. 
08. MACHADO, O.V. de M. Ensino de ciências na escola de 1 grau: visão de ciência veiculada pelos alunos. São Paulo, 1989. 148p. Dissertação (Mestrado) - Pontifícia Universidade Católica de São Paulo.

09. MARTINS, J.; BICUDO, M.A.V. A pesquisa qualitativa em psicologia: fundamentos e recursos básicos. São Paulo: Moraes/ EDUC, 1989.

10. OLSCHOWSKY, A. Integração docente assistencial: um estudo de caso. Ribeirão Preto, 1995. 179p. Dissertação (Mestrado) - Escola de Enfermagem de Ribeirão Preto, Universidade de São Paulo.
11. PADILHA, M.I.C.S. Análise Crítica das causas da Integração e/ou desintegração docente assistencial na Enfermagem. Rev. Gaúch. Enfermagem, v. 12, n. 1, p. 33-37, 1991.

12. PIRES. L.S. et al. Importância da Integração docente Assistencial: uma tentativa realizada em um Hospital Militar. Rev. Bras. Enfermagem, v. 35 p. 35-95, 1982.

13. REZENDE, A.L.M. Saúde: a dialética do pensar e do fazer. 2.ed. São Paulo: Cortez, 1989.

14. TORRES, I.M. et al. Internato de Enfermagem e nutrição uma modalidade de integração docente assistencial. Rev. Bras. Enfermagem, v. 37, n. 314, p. 280-289, 1984. 